\title{
THE ROLE OF DIETARY AND LIFESTYLE FACTORS IN THE DEVELOPMENT OF COLORECTAL CANCER: CASE CONTROL STUDY IN MINIA, EGYPT
}

\author{
Eman Mohamed Mahfouz ${ }^{1}$, Refaat Raouf Sadek¹, Wafaa Mohamed Abdel-Latief ${ }^{2}$, Fadia Abdel-Hamed Mosallem¹, \\ Ebtesam Esmail Hassan ${ }^{1}$ \\ ${ }^{1}$ Public Health and Preventive Medicine Department, Faculty of Medicine, Minia University, Egypt \\ ${ }^{2}$ Medical Oncology Department, Faculty of Medicine, Minia University, Egypt
}

\section{SUMMARY}

Background: Colorectal cancer (CRC) is the third most common cancer worldwide, after lung and breast cancer, and is associated with the population dietary and lifestyle factors.

Aim: To determine the relation between dietary and lifestyle factors and development of CRC in patients attending Minia oncology centre and compare them with their control.

Methods: Study included $150 \mathrm{CRC}$ patients attending Minia oncology centre and 300 control subjects matched by age and sex. Subjects participating in the study filled in a questionnaire including questions about socio-demographic data, medical data concerning $C R C$ and its treatment as well as dietary and lifestyle factors.

Results: The most significant dietary and lifestyle $C R C$ risk factors were higher consumption of red meat $(O R=57.1)$, preserved food $(O R=39.4)$, artificial sweeteners $(O R=20.8)$, fast foods $(O R=12.8)$, soft drinks $(O R=4.6)$, spicy foods $(O R=4.2)$, processed meat $(O R=2.4)$, and smoking $(O R=8.8)$. The most significant protective factors were physical activity $(O R=0.001)$, calcium rich diet $(O R=0.08)$, higher consumption of fruits and vegetable $(O R=0.02$ ), cruciferous vegetables (broccoli $O R=0.11$, cauliflower $O R=0.30$ and cabbage $O R=0.30$ ), high fiber bread $(O R=0.15)$, fruit juice $(O R=0.18)$, and sea foods (tuna $O R=0.28$ and fish $O R=0.38$ ).

Conclusion: Sedentary lifestyle and unhealthy dietary choices were prevalent among CRC cases. This study provides strong evidence that lifestyle and dietary modification are important factors in the prevention of colorectal cancer.

Key words: colorectal cancer, life style, diet, case-control study, Minia

Address for correspondence: E. M. Mahfouz, Public Health and Preventive Medicine Department, Faculty of Medicine, Minia University, Minia, Egypt. E-mail: emanmahfouz39@yahoo.com

\section{INTRODUCTION}

Colorectal cancer $(\mathrm{CRC})$ is the third most common cancer worldwide after lung and breast; it is the third most common cancer in men after lung and prostate cancer and the second in women after breast cancer. It was estimated that 1.23 million new cases of CRC were diagnosed in 2008 worldwide (1).

The global annual incidence of CRC is approximately one million cases and its annual mortality is more than five hundred thousand (WHO, 2011) (2). In Egypt, the relative frequency of CRC is about 9-12\% with high male predominance 3:1 (Mokhtar, 2010) (3). According to the Egypt National Cancer Registry, age-specific incidence rates of CRC per 100,000 were 6.3 for males and 4.3 for females in 2009. According to Minia Cancer Registry in 2011, the crude incidence rate of CRC was about 3.4 per 100,000 population in Minia (4).

The concept of "lifestyle" is based on the idea that people generally exhibit a recognizable pattern of behaviour in their everyday lives, the WHO definition (5) of lifestyle providing a broader understanding of the determinants of a healthy lifestyle stated that lifestyle is a way of living based on identifiable patterns of behaviour which are determined by the interplay between the individual personal characteristics, social interactions, and socioeconomic and environmental living conditions (6).

Life style factors associated with risk of CRC include smoking, alcohol intake, high red meat and processed meat consumption, high fat and protein diet intake, physical inactivity, and overweight $(7,8)$. According to the National Institute for Clinical Excellence, about three quarters of CRC cases are associated with the population lifestyle (9).

Alterations and changes in the traditional Egyptian diet, introduction of new types of foods and eating habits such as consumption of processed or semi-processed, tinned or cooked meats, fried potatoes, hamburger, and pizza are taking place. Fast foods became popular as well as physical inactivity and smoking which might lead to increasing CRC among Egyptian population (10). Therefore, a study was conducted with the aim of determining the relation between lifestyle factor and development of CRC in patients attending Minia oncology centre. 


\section{MATERIALS AND METHODS}

\section{Study Design: Case Control Study}

Administrative and ethical consideration: An approval was obtained from the Ministry of Health and a manager of Minia oncology centre to attain data about number of CRC patients attending the centre during the previous years and to facilitate data collection through a questionnaire. A written informed consent was obtained from each participant.

\section{Study Population}

Selection of cases: Inclusion criteria - primary CRC cases of either sex without age restriction receiving treatment (i.e. surgery, chemotherapy, radiotherapy, or combination of these therapies) in Minia oncology centre from October 2010 to June 2011 were recruited. Exclusion criteria - cases with family history of CRC, patients with a primary cancer other than CRC and severely ill cases.

Selection of control: Inclusion criteria - 300 age and sex matched controls were selected randomly from community where the cases lived during the period from June 2011 to August 2011. Exclusion criteria - relatives or cases and individuals with family history of colorectal cancer.

Collection of data: Data were collected through a questionnaire. Questions dealt with issues such as socio-demographic characteristics (age, gender, residence, educational level, occupation, and marital status); medical data concerning disease (its duration and CRC site and received therapy); and life style factors concerning dietary history - dietary pattern during 2 years prior to cancer diagnosis was assessed through the dietary questionnaire introduced by Melbourne University (11). This food frequency questionnaire includes eight food items: cereal foods, dairy products, meat and fish, fruits, vegetables, egg, drinks, and sweets. The analysis of each food item includes the frequency of intake daily, weekly or monthly; the number of servings for each food item and conversions of household measures and serving sizes of various foods into grams (12). Life style factors concerning smoking history included type of smoking, duration of smoking, number of cigarettes per day and smoking index, i.e. total number of cigarettes per day (other types as shish converted into cigarette unit) multiplied by the duration of smoking, passive smoking, quitting smoking and reasons for it. Other questions inquired about history of alcohol intake and history of physical activity (performing regular exercise, type and the frequency per week).

Anthropometric measurements included weight and height and calculated BMI.

\section{Statistical Analysis}

Statistical analysis was performed using SPSS 13 and quantitative data (mean and standard deviation), qualitative data (frequency distribution) were measured. Chi square test and Fisher's

Table 1. CRC cases and controls according to their age and sex, Minia governorate, October 2010 to August 2011

\begin{tabular}{|c|c|c|c|c|c|c|}
\hline \multirow{2}{*}{ Data } & & \multicolumn{2}{|c|}{ CRC cases } & \multicolumn{2}{|c|}{ Control } & \multirow{2}{*}{$p$} \\
\hline & & N & $\%$ & N & $\%$ & \\
\hline \multirow[t]{4}{*}{ Age groups } & $<20$ year & 4 & 2.7 & 6 & 2.0 & \multirow{4}{*}{$0.3^{\mathrm{a}}$} \\
\hline & $20-40$ year & 45 & 30.0 & 102 & 34.0 & \\
\hline & $40-60$ year & 80 & 53.3 & 136 & 45.3 & \\
\hline & $>60$ year & 21 & 14.0 & 56 & 18.7 & \\
\hline \multirow[t]{2}{*}{ Sex } & Male & 72 & 48.0 & 144 & 48.0 & \multirow{2}{*}{$1^{b}$} \\
\hline & Female & 78 & 52.0 & 156 & 52.0 & \\
\hline \multirow[t]{2}{*}{ Residence } & Urban & 58 & 38.7 & 116 & 38.7 & \multirow{2}{*}{$1^{b}$} \\
\hline & Rural & 92 & 61.3 & 184 & 61.3 & \\
\hline \multirow[t]{4}{*}{ Marital status } & Single & 16 & 10.7 & 27 & 9.0 & \multirow{4}{*}{$0.2^{\mathrm{a}}$} \\
\hline & Married & 117 & 78.0 & 250 & 83.8 & \\
\hline & Widow & 16 & 10.7 & 23 & 7.7 & \\
\hline & Divorced & 1 & 0.7 & 0.0 & 0.0 & \\
\hline \multirow[t]{4}{*}{ Education level } & Illiterate & 87 & 58.0 & 162 & 54.0 & \multirow{4}{*}{$0.1^{b}$} \\
\hline & Read and write & 17 & 11.4 & 50 & 16.7 & \\
\hline & Secondary & 38 & 25.3 & 82 & 27.3 & \\
\hline & University and higher & 8 & 5.3 & 6 & 2.0 & \\
\hline \multirow{4}{*}{ Occupation } & Unemployed & 110 & 73.3 & 246 & 82.0 & \multirow{4}{*}{$0.09^{b}$} \\
\hline & Clerical & 6 & 4.0 & 9 & 3.0 & \\
\hline & Manual & 25 & 16.7 & 27 & 9.0 & \\
\hline & Professional & 9 & 6.0 & 18 & 6.0 & \\
\hline Total & & 150 & 100.0 & 300 & 100.0 & \\
\hline
\end{tabular}

${ }^{a}$ Fisher exact $=3.2$ and $3.6, \mathrm{DF}=3$ and, ${ }^{b} \mathrm{x}^{2}=0.000,0.000,5.9$ and $6.3, \mathrm{DF}=1,1,3$ and 3 
exact test was used to compare proportions. Student t-test was used to compare two means. Odds ratio was calculated to predict the risky and protective factors in relation to CRC. Multiple regression analysis was used to determine the combined effect of different independent variables on the target (dependant variable). The probability of less than 0.05 was used as a cut off point for all significant tests.

\section{RESULTS}

It was found that more than half $(53.3 \%)$ of CRC patients were aged $40-60$ years, $52 \%$ of colorectal cancer cases were females, $61.3 \%$ of CRC patients were living in rural areas, $78 \%$ were married, $58 \%$ were illiterate, and $73.3 \%$ were unemployed (Table 1). Colon cancer accounted for $52 \%$ of the total of CRC cases. Sigmoid region is the most CRC afflicted part of colon (42.4\%), followed by ceacum (24.4\%), and the other sites. Majority (75\%) of rectal cancer is located in lower rectum (Table 2).

Both active and passive smoking was found to be significantly more frequent in CRC patients than in their controls (34\% vs. $18.7 \%$ and $24.7 \%$ vs. $5.3 \%$, respectively). All patients were cat- egorized as physically inactive compared to $78.3 \%$ of controls $(p=0.001)$ (Table 3a).

Red meat consumption was found to be higher among patients $(801.7 \pm 710.8$ grams per week) than among controls (234.6 \pm 110.8 grams per week) and this difference was statistically significant $(\mathrm{p}=0.001)$. The same was noted for processed meat consumption by CRC patients $(629.03 \pm 337.8)$ than by controls $(186.7 \pm 83.2)$ (statistically significant difference $\mathrm{p}=0.006)$. More than half $(57.3 \%)$ of controls ate salmon and sardine once or more times a week compared to $22.7 \%$ of patients $(p=0.008)$. Intake of calcium rich diet was higher among controls (64.3\%) than among patients (36.7\%). $40.7 \%$ of controls ate more than five servings of fruits and vegetables per day compared to $2.7 \%$ of patients only and this difference was statistically significant $(p=0.001)$. Daily consumption of spicy foods was higher among patients $(67.3 \%)$ compared to $5.7 \%$ of controls, this difference was statistically significant $(p=0.004) .27 .7 \%$ of patients consumed preserved food daily compared to $10 \%$ of controls $(0.001) .10 \%$ of patients consume fast foods daily compared to only $2 \%$ of controls $(p=0.001)$. About half $(48.7 \%)$ of patients consumed soft drinks daily compared to $15 \%$ of controls, this difference was statistically significant $(p=0.001)$. Daily consumption of fruit juice was

Table 2. CRC cases according to classification and distribution of cancer, Minia Oncology Centre, October 2010 to June 2011

\begin{tabular}{|c|c|c|c|}
\hline \multicolumn{2}{|c|}{ Classification and distribution of CRC } & \multirow{2}{*}{$\begin{array}{c}\mathbf{N} \\
15\end{array}$} & \multirow{2}{*}{$\begin{array}{c}\% \\
19.2\end{array}$} \\
\hline Colon & Ascending colon & & \\
\hline & Transverse colon & 4 & 5.1 \\
\hline & Ascending colon and transverse colon & 1 & 1.3 \\
\hline & Caecum & 19 & 24.4 \\
\hline & Descending & 6 & 7.7 \\
\hline & Sigmoid & 33 & 42.4 \\
\hline & Total & 78 & 52.0 \\
\hline \multirow[t]{3}{*}{ Rectum } & Upper rectum & 11 & 25.0 \\
\hline & Lower rectum & 33 & 75.0 \\
\hline & Total & 44 & 29.3 \\
\hline Colorectal & Recto sigmoid & 28 & 18.7 \\
\hline \multicolumn{2}{|l|}{ Total } & 150 & 100.0 \\
\hline
\end{tabular}

Table 3a. Relation between lifestyle factors and CRC among cases and controls, Minia governorate, October 2010 to August 2011

\begin{tabular}{|c|c|c|c|c|c|c|}
\hline \multirow{2}{*}{\multicolumn{2}{|c|}{ Data }} & \multicolumn{2}{|c|}{ CRC cases } & \multicolumn{2}{|c|}{ Control } & \multirow{2}{*}{$p$} \\
\hline & & \multirow{2}{*}{$\begin{array}{l}\mathbf{N} \\
62 \\
\end{array}$} & \multirow{2}{*}{$\begin{array}{c}\% \\
41.3 \\
\end{array}$} & \multirow{2}{*}{$\begin{array}{c}\mathbf{N} \\
228\end{array}$} & \multirow{2}{*}{$\begin{array}{c}\% \\
76.0 \\
\end{array}$} & \\
\hline Smoking history & Non smoker & & & & & \multirow{3}{*}{$0.005^{b}$} \\
\hline & Smoker & 51 & 34.0 & 056 & 18.7 & \\
\hline & Passive smoker & 37 & 24.7 & 016 & 5.3 & \\
\hline \multirow[t]{3}{*}{ Physical activity } & Inactive & 150 & 100 & 235 & 78.3 & \multirow{3}{*}{$0.001^{a}$} \\
\hline & Moderately active & 0 & 0.0 & 12 & 4.0 & \\
\hline & Severely active & 0 & 0.0 & 53 & 17.7 & \\
\hline \multirow[t]{2}{*}{ Alcohol intake } & Never & 147 & 98.0 & 291 & 97.0 & \multirow{2}{*}{$0.700^{b}$} \\
\hline & Rarely & 3 & 2 & 9 & 3 & \\
\hline \multicolumn{2}{|l|}{ Total } & 150 & 100.0 & 300 & 100.0 & \\
\hline
\end{tabular}

${ }^{a}$ Fisher exact (DF) = 37.9(2), 125.1(1), 71.6(1), 151.3(4), 206.3(5), 15.6(3), ${ }^{b} x^{2}(D F)=52.05(2), 19.3(1), 47.03(1), 70.9(2), 0.38(1), 58(1)$ and 28.5(1) 
Table 3b. Relation between dietary factors and CRC among cases and controls, Minia governorate, October 2010 to August 2011

\begin{tabular}{|c|c|c|c|c|c|c|}
\hline \multirow{2}{*}{\multicolumn{2}{|c|}{ Data }} & \multicolumn{2}{|c|}{ CRC cases } & \multicolumn{2}{|c|}{ Control } & \multirow{2}{*}{$\mathrm{p}$} \\
\hline & & \multirow{2}{*}{$\begin{array}{l}\mathbf{N} \\
89\end{array}$} & \multirow{2}{*}{$\begin{array}{c}\% \\
59.3 \\
\end{array}$} & \multirow{2}{*}{$\frac{\mathrm{N}}{297}$} & \multirow{2}{*}{$\begin{array}{c}\% \\
99\end{array}$} & \\
\hline \multirow{4}{*}{$\begin{array}{l}\text { Red meat } \\
\text { (grams/week) }\end{array}$} & $\leq 500 \mathrm{~g}$ & & & & & \multirow{2}{*}{$0.001^{\mathrm{a}}$} \\
\hline & $>500 \mathrm{~g}$ & 61 & 40.7 & 003 & 1 & \\
\hline & Range & \multicolumn{2}{|c|}{$120-5,510$} & \multicolumn{2}{|c|}{$0-700$} & \\
\hline & Mean (SD) & \multicolumn{2}{|c|}{$801.7 \pm 710.8$} & \multicolumn{2}{|c|}{$234.6 \pm 110.8$} & $0.001^{\mathrm{c}}$ \\
\hline & $\leq 25 \mathrm{~g}$ & 50 & 33.3 & 249 & 83 & $\cap 001 \mathrm{~b}$ \\
\hline & $>25 \mathrm{~g}$ & 100 & 66.7 & 51 & 17 & 0.001 \\
\hline & Range & \multicolumn{2}{|c|}{$0-3,570$} & \multicolumn{2}{|c|}{$0-1,108$} & \\
\hline & Mean (SD) & \multicolumn{2}{|c|}{$629.03 \pm 337.8$} & \multicolumn{2}{|c|}{$186.7 \pm 83.2$} & $0.006^{c}$ \\
\hline \multirow{2}{*}{ Fresh fish } & Less than once per week & 106 & 70.7 & 145 & 48.3 & \multirow{2}{*}{$0.001^{b}$} \\
\hline & Once or more per week & 044 & 29.3 & 155 & 51.7 & \\
\hline \multirow{2}{*}{ Canned fish } & Less than once per week & 116 & 77.3 & 128 & 42.7 & \multirow{2}{*}{$0.008^{b}$} \\
\hline & Once or more per week & 34 & 22.7 & 172 & 57.3 & \\
\hline \multirow{3}{*}{ Calcium rich diet } & Low intake & 88 & 58.6 & 59 & 19.7 & \multirow{3}{*}{$0.001^{b}$} \\
\hline & Moderate intake & 7 & 4.7 & 48 & 16 & \\
\hline & High intake & 53 & 36.7 & 193 & 64.3 & \\
\hline \multirow{2}{*}{ Fruits and vegetables } & $\leq 5$ servings per day & 146 & 97.3 & 178 & 59.3 & \multirow{2}{*}{$0.001^{\mathrm{a}}$} \\
\hline & $>5$ servings per day & 004 & 2.7 & 122 & 40.7 & \\
\hline \multirow{5}{*}{ Spicy food (e.g. chili) } & No & 039 & 26 & 208 & 69.3 & \\
\hline & Rarely & 0.0 & 0.0 & 018 & 6.0 & \\
\hline & $1-2$ per week & 003 & 2.0 & 041 & 13.7 & $0.004^{a}$ \\
\hline & 3-6 per week & 007 & 4.7 & 016 & 5.3 & \\
\hline & Daily & 101 & 67.3 & 017 & 5.7 & \\
\hline & No & 20 & 18.5 & 219 & 73 & \\
\hline & Rarely & 02 & 1.9 & 021 & 7.0 & \\
\hline Preserved foods & $1-2$ per week & 45 & 41.7 & 020 & 6.7 & $0.001^{a}$ \\
\hline & 3-6 per week & 11 & 10.2 & 010 & 3.3 & \\
\hline & Daily & 50 & 27.7 & 030 & 10 & \\
\hline & No & 119 & 79.3 & 260 & 86.7 & \\
\hline Foet fordc & $1-2$ per week & 012 & 8.0 & 020 & 6.7 & 001 a \\
\hline 1 ast incus & 3-6 per week & 004 & 2.7 & 014 & 4.7 & 0.001 \\
\hline & Daily & 015 & 10 & 006 & 2.0 & \\
\hline Soft drink & Yes & 73 & 48.7 & 45 & 15 & $001 \mathrm{~b}$ \\
\hline 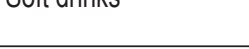 & No & 77 & 51.3 & 255 & 85 & 0.001 \\
\hline Fruitiuice & Yes & 011 & 7.3 & 089 & 29.7 & $\cap 001 \mathrm{~b}$ \\
\hline fruin juive & No & 139 & 92.7 & 211 & 70.3 & 0.001 \\
\hline Total & & 150 & 100.0 & 300 & 100.0 & \\
\hline
\end{tabular}

${ }^{a}$ Fisher exact $(D F)=125.1(1), 71.6(1), 206.3(5), 151.3(4)$ and 15.6(3), ${ }^{b} X^{2}(D F)=19.3(1), 47.03(1)$ and 70.9(2), 58.5(1) and 28.5(1), ${ }^{c t}(D F)=13.5(448)$ and 21.4(448)

higher among controls (29.7\%) than among CRC patients (7.3\%) and this difference was statistically significant $(\mathrm{p}=0.001)$ (Table $3 b)$. Table 4 shows that the frequency of obesity was higher among patients $(20.7 \%)$ than controls $(16.7 \%)(p=0.007)$.

Data in Table 5 show that higher consumption of red meat, preserved food, artificial sweeteners, fast foods, soft drinks, spicy foods, processed meat, and smoking were significantly related to onset of CRC. The odds of higher consumption of red meat (more than $500 \mathrm{~g} /$ week) among CRC patients was 57.1 compared to controls, the odds of frequent consumption of preserved foods among patients was 39.4 compared to controls, the odds of use of artificial sweeteners among patients was 20.8 , the odds of frequent consumption of fast foods among patients was 12.8 than among controls, the odds of smoking was 8.8 times among patients than among controls. It was found that the most protective factor was physical activity (odds ratio $=0.001, \mathrm{p}=0.001$ ) followed by high consumption of fruits and vegetables (odds ratio $=0.04, p=0.001$ ) (Table 6). 
Table 4. Relation between anthropometric measures and CRC among cases and controls, Minia governorate, October 2010 to August 2011

\begin{tabular}{|c|c|c|c|}
\hline \multirow{2}{*}{ BMI } & CRC patients $(\mathrm{N}=150)$ & Control (N=300) & \multirow{2}{*}{$\mathrm{p}$} \\
\hline & $\mathrm{n}(\%)$ & $\mathrm{n}(\%)$ & \\
\hline Under weight & $11(7.3)$ & $7(2.4)$ & \multirow{4}{*}{0.007} \\
\hline Normal weight & 77 (51.3) & $146(48.7)$ & \\
\hline Over weight & $31(20.7)$ & $97(32.3)$ & \\
\hline Obese & $31(20.7)$ & $50(16.7)$ & \\
\hline
\end{tabular}

Table 5. Multiple regression analysis of life style factors increasing the occurrence of CRC among cases attending Minia oncology centre, October 2010 to June 2011

\begin{tabular}{|l|c|c|c|c|}
\hline Variables & Beta & Odds ratio (OR) & $95 \% \mathrm{Cl}$ & $\mathbf{p}$ \\
\hline Red meat $>500$ g/week & 4.04 & 57.1 & $12.1-270.3$ & 0.001 \\
\hline Preserved food & 3.6 & 39.4 & $15.5-100.1$ & 0.001 \\
\hline Artificial sweeteners & 3.03 & 20.8 & $2.7-159.7$ & 0.003 \\
\hline Fast foods & 2.5 & 12.8 & $3.8-39.1$ & 0.002 \\
\hline Smoking & 2.1 & 8.8 & $3.9-19.3$ & 0.001 \\
\hline Soft drink & 1.5 & 4.6 & $1.9-11.01$ & 0.001 \\
\hline Spicy foods & 1.4 & 4.2 & $1.7-9.9$ & 0.001 \\
\hline Processed meat & 0.89 & 2.4 & $1.5-3.8$ & 0.001 \\
\hline Pickles & 0.43 & 1.5 & $0.5-4.3$ & 0.400 \\
\hline Tea & 0.44 & 1.3 & $0.8-2.1$ & 0.300 \\
\hline Obesity & 0.26 & 1.3 & $0.7-2.1$ & 0.200 \\
\hline Alcohol & 0.99 & 1.1 & $0.8-1.2$ & 0.500 \\
\hline
\end{tabular}

N.B. the dependant variable is $C R C, R^{2}=0.76$

Table 6. Multiple regression analysis of life style factors protecting from the occurrence of CRC among patients attending Minia oncology centre, October 2010 to June 2011

\begin{tabular}{|c|c|c|c|c|}
\hline Variables & Beta & Odds ratio (OR) & $95 \% \mathrm{Cl}$ & $\mathrm{p}$ \\
\hline Physical activity & 8.7 & 0.001 & $0.001-0.0002$ & 0.001 \\
\hline More than five fruits and raw vegetable servings per day & 3.6 & 0.02 & $0.008-0.09$ & 0.001 \\
\hline High calcium diet & 2.7 & 0.08 & $0.04-0.17$ & 0.001 \\
\hline Broccoli (once or more per week) & 2.1 & 0.11 & $0.01-0.48$ & 0.030 \\
\hline High fiber bread & 1.8 & 0.15 & $0.04-0.52$ & 0.003 \\
\hline Fruit juice & 1.6 & 0.18 & $0.09-0.36$ & 0.001 \\
\hline Canned fish (once or more per week) & 1.2 & 0.28 & $0.14-0.55$ & 0.001 \\
\hline Cauliflower (once or more per week) & 1.2 & 0.30 & $0.20-0.46$ & 0.001 \\
\hline Cabbage (once or more per week) & 1.07 & 0.34 & $0.22-0.52$ & 0.001 \\
\hline Fresh fish (once or more per week) & 0.94 & 0.38 & $0.25-0.59$ & 0.001 \\
\hline
\end{tabular}

N.B. the dependant variable is $C R C, R^{2}=0.64$.

\section{DISCUSSION}

$\mathrm{CRC}$ is cancer of the colon and rectum arising from their mucosal lining. It is the third most commonly diagnosed cancer after lung and breast worldwide (1) and smoking is believed to play a great role in CRC incidence (13).

To determine the relation between dietary and lifestyle factors (dietary pattern, smoking, physical activity, and alcohol intake) and development of CRC, a control case study was carried out among CRC patients attending Minia oncology centre from Oc- tober 2010 to June 2011. Cancer patients often pursue lifestyle and dietary changes with the aim to improve treatment outcomes, so the questionnaire assessed dietary history and pattern of their habits and lifestyle during 2 years prior to cancer diagnosis.

The age and sex were matched between cases and controls, their age ranged between $16-80$ years with mean $46.1 \pm 13.9$ and $46.7 \pm 17.5$, respectively, the majority of them falling into the age group of $40-60$ years $(53.3 \%$ cases and $45.3 \%$ controls), which was in agreement with Almurshed (14) who studied sociodemographic, life style and anthropometric parameters and CRC 
in a case control study in Riyadh and found that $54 \%$ of cases were $40-60$ years old and $46 \%$ of controls were falling into the same age group. About half of the cases and controls were females (52\%) and $48 \%$ were males. Regarding other socio-demographic data, $61.3 \%$ of cases came from rural areas, $78 \%$ were married, $58 \%$ were illiterate, and $73.3 \%$ were unemployed which was similar to results reported by Almurshed, who found that $86 \%$ of cases were married, $44 \%$ were illiterate and $54 \%$ were unemployed (14).

We observed that the most common site of CRC was distal part of colon $(74 \%)$, followed by proximal one $(26 \%)$, these findings correspond with results reported by Duijnhoven et.al. (15) who found that $27.1 \%$ of CRC cases were proximal and $72.9 \%$ were distal cancer. About $60 \%$ of CRC cases arise in the distal part of colon in countries where colonic cancer incidence is high (7). In this study Hansen revealed that $42.4 \%$ of colon cancer occurred in the sigmoid region, $75 \%$ of rectal cancer was in the lower rectum and $18.7 \%$ was recto sigmoid.

In our study, we observed that there was a significant difference between CRC cases and controls regarding history of smoking, as $34 \%$ of cases versus $18.7 \%$ of controls were smokers and $24.7 \%$ of cases were passive smokers compared to only $5.3 \%$ of controls. This was in agreement with Limsui et al. (16), who conducted a prospective study on the relation between cigarette smoking and CRC risk and found that $34 \%$ of those who develop CRC were smokers. Similar findings were reported by Abdulbari et al. (17), who carried out a case control study on lifestyle habits and CRC risk in Qatar and found that $26.7 \%$ of cases and $17 \%$ of controls were smokers.

All cases $(100 \%)$ examined in this study were physically inactive, while $78.3 \%, 4 \%$ and $17.7 \%$ of controls were inactive, moderately and severely active, respectively, and these differences were statistically significant. These findings are in agreement with Arafa et al. (18), who found that $75.7 \%, 7.7 \%$ and $16.8 \%$ of controls were inactive, moderately and severely active, respectively, and approximately the same what reported by Almurshed (14), who found that $100 \%$ of cases were physically inactive and $54 \%$, $33 \%$ and $13 \%$ of controls were inactive, moderately and severely active, respectively.

This study showed that red meat consumption was significantly higher (801.7 \pm 710.8 grams per week) among cases than among controls (234.6 \pm 110.8 grams per week), more than one third of patients $(40.7 \%)$ ate more than $500 \mathrm{~g}$ of red meat per week compared to $1 \%$ of controls. This was in agreement with Alexander and Cushing (19), who conducted critical summary of prospective epidemiologic studies of red meat consumption and found positive association between red meat consumption and CRC. The World Cancer Research Fund (WCRF) recommends that red meat consumption should be less than 500 grams per week.

We observed that there was a significant relation between processed meat consumption and CRC as its consumption was higher among cases $(629.03 \pm 337.8$ grams per week $)$ than among controls (186.7 \pm 83.2 grams per week), consumption of more than 250 grams per day of processed meat was higher (66.7\%) among cases than among controls (17\%). This was in agreement with Santarelli et al. (21), who conducted systematic review on multiple observational and experimental studies which assessed the relation between processed meat consumption and $\mathrm{CRC}$ and reported that processed meat intake increases CRC risk. Abdulbari et al. (17) also found that daily consumption of processed meat was higher
(20.9\%) among cases than in controls (17.1\%). WCRF reported that consumption of more than 250 grams per day of processed meat increase the risk of CRC (20).

We also found that sea food consumption was significantly higher among controls than among cases, eating fish once or more per week was higher among controls (51.7\%) compared to $29.3 \%$ of cases and more than half $(57.3 \%)$ of controls ate canned fish once or more per week compared to $22.7 \%$ of cases. This was in agreement with Hall et al. (22), who studied fish, n-3 fatty acid intake and CRC in men in 22 years prospective study and found that fish intake was inversely associated with the risk of CRC, similarly to what was determined by Sanjoaquin et al. (23), who carried out a prospective study on lifestyle and CRC incidence and found that only $33.6 \%$ of CRC cases ate fish once or more a week.

This study showed that consumption of calcium rich diet was higher among controls (64.3\%) compared to $36.7 \%$ of cases, and consumption of lower amount of calcium was higher among cases $(58.6 \%)$ than in controls $(19.7 \%)$. This was in agreement with Mizoue et al. (24), who found that mean calcium rich foods intake was higher among controls (200 grams per day) compared to cases (167 grams per day) and that only $34.8 \%$ of CRC cases consumed calcium rich food compared to $40.9 \%$ of controls.

Eating more than five servings per day was higher among controls (40.7\%) than among cases $(2.7 \%)$. This was in agreement with Arafa et al. (18), who found that eating more than five servings per day was higher among controls (45.9\%) than cases (33.6\%).

We found that consumption of spicy foods and preserved foods was significantly higher among cases than among controls, daily consumption of spicy foods was higher among cases (67.3\%) compared to $5.7 \%$ among controls, which was in agreement with Nayak et al. (25), who conducted a case control study on the role of diet in CRC in India and found strong positive association between spices and CRC. Regarding preserved foods, its daily consumption was higher among cases $(27 \%)$ than among controls $(10 \%)$. These findings were in agreement with Chiu et al. (26), who studied dietary factors and CRC in China and found that the risk of colon cancer increased significantly with increasing consumption of preserved foods.

This study showed that there was no significant difference regarding alcohol consumption between cases and controls, similarly to findings by Sriamporn et al. (27), who studied risk factors for CRC in Northeast Thailand and found that the risk associated with alcohol consumption did not achieve statistical significance. Squires et al. (28) did not find any significant differences between cases and controls for males and females regarding mean alcohol consumption per day.

Daily consumption of soft drinks was significantly higher among cases $(48.7 \%)$ than in controls (15\%), similarly to results reported by Abdulbari et al. (17), who found that daily soft drink intake was significantly higher among cases $(28.7 \%)$ in comparison to controls (18.8\%). Fruit juice consumption was significantly higher among controls $(29.7 \%)$ compared to $7.3 \%$ of cases.

We also observed that frequency of obesity was higher in cases $(20.7 \%)$ than in controls $(16.7 \%)$. This approximates to what was reported by Slattery et al. (29), who studied physical activity and CRC and found that obesity was higher in cases $(21.3 \%)$ than in controls (18\%), as well as by Hu et al. (30), who found that $21.2 \%$ of cases were obese compared to $14.4 \%$ of controls. Sun et al. (31) studied the association of total energy intake and macronutrient 
consumption with CRC risk and found that obesity was higher among cases $(22.4 \%)$ in comparison to controls (18.5\%). Williams et al. (32) studied dietary patterns and rectal cancer risk in white Americans and African-Americans and found that obesity was higher in cases (39\%) than in controls $(29 \%)$.

It was observed in the study that higher consumption of red meat $(\mathrm{OR}=57.1)$, preserved food $(\mathrm{OR}=39.4)$, artificial sweeteners $(\mathrm{OR}=20.8)$, fast foods $(\mathrm{OR}=12.8)$, soft drinks $(\mathrm{OR}=4.6)$, spicy foods $(\mathrm{OR}=4.2)$, processed meat $(\mathrm{OR}=2.4)$, and smoking $(\mathrm{OR}=8.8)$ constitute significant risk for CRC. Almurshed (14) found that higher red meat consumption $(\mathrm{OR}=44)$ is associated with increased CRC risk. Chiu et al. (26) found that preserved food increase the risk of $\mathrm{CRC}(\mathrm{OR}=2$ among males and 2.7 among females). Giles (11) found that OR of artificial sweeteners for colon and rectal cancer was 1.07 and 1.1, respectively, among men, and 1.02 and 1.04 for colon and rectal cancer, respectively, among those with BMI less than $25 \mathrm{~kg} / \mathrm{m}^{2}$. Abdulbari et al. (17) found that smoking $(\mathrm{OR}=2.12)$ and soft drinks $(\mathrm{OR}=1.62)$ increase the risk of CRC. Similarly, Nayak et al. (25) found that OR of spices was 9.62. Chiu and Gapstur (33) investigated the effect of dietary changes during adult life and found that OR of high processed meat intake was 3.7. Ramadas and Kandiah (34) found that fast foods are associated with $\mathrm{CRC}$ risk $(\mathrm{OR}=1.96)$.

This study showed that physical activity $(\mathrm{OR}=0.001)$, higher consumption of fruits and vegetable $(\mathrm{OR}=0.02)$, calcium rich diet $(\mathrm{OR}=0.08)$, cruciferous vegetables (broccoli $\mathrm{OR}=0.11$, cauliflower $\mathrm{OR}=0.30$ and cabbage $\mathrm{OR}=0.30)$, high fiber bread $(\mathrm{OR}=0.15)$, fruit juice $(\mathrm{OR}=0.18)$, and sea foods (tuna $\mathrm{OR}=0.28$ and fish $\mathrm{OR}=0.38$ ) lower the risk of $\mathrm{CRC}$. This was in agreement with Almurshed (14), who found that physical activity $(\mathrm{OR}=0.14)$ had protective effect. Nayak et al. (25) found that OR for high fruits and vegetable consumption was 0.15 and Duijnhoven et al. (15) found that the risk of CRC related to high fruits and vegetable consumption was 0.86 . Nashar and Almurshed (35) found that calcium rich diet $(\mathrm{OR}=0.75)$, cruciferous vegetables (broccoli $\mathrm{OR}=0.12$, and cabbage $\mathrm{OR}=0.21)$, high fiber food $(\mathrm{OR}=0.11)$, and fruit juice (0.14) had protective effect. Mizoue et al. (24) found that high intake of calcium rich foods as milk had protective effect with regard to $\mathrm{CRC}(\mathrm{OR}=0.60)$. Hall et al. (22) found that the relative risk of sea food consumption was 0.76 for fish and 0.95 for tuna fish.

\section{CONCLUSIONS}

These results indicated that the CRC cases enrolled in this study were adopting a sedentary lifestyle and their dietary pattern was characterized by unhealthy diet. Thus the study hypothesis that $\mathrm{CRC}$ is strongly related to the life style of population may be accepted. Personalized, evidence based, and guidance on healthy lifestyle choices appear to be a much needed part of preventive community interventions and care planning to survivors. Nutrition education programmes about role of diet in development or protection from $\mathrm{CRC}$ as well as preventing obesity through the promotion of healthy eating and fostering daily physical activity are greatly needed.

\section{Conflict of Interests}

None declared

\section{Authors' Contributions}

All authors contributed substantially to the study conception and design, data collection and analysis, and drafting and revision of the article. All approved the final version to be published.

\section{REFERENCES}

1. Ferlay J, Shin HR, Bray F, Forman D, Mathers C, Parkin DM. GLOBOCAN 2008 v2.0, Cancer incidence and mortality worldwide: IARC CancerBase No. 10 [Internet]. Lyon: International Agency for Research on Cancer; 2010 [cited 2012 Jul 12]. Available from: http://globocan. iarc.fr.

2. World Health Organization. Media centre. Global cancer rates could increase by $50 \%$ to 15 million by 2020 [Internet]. Geneva: WHO; 2003 [cited 2011 May 5]. Available from: http://www.who.int/mediacentre/ news/releases/2003/pr27/en/.

3. Mokhtar N. Screening and early diagnosis of colorectal cancer [Internet]. [cited 2010 May 30]. Available from: http://www.nci.cu.edu.eg/lectures/ Colorectal\%20Cancer.pdf.

4. National Cancer Registry Program of Egypt. Reports and statistics. ELMinia 2009 [Internet]. Ministry of Communications and Information Technology; 2010 [cited 2011 Oct 15]. Available from: http://www. cancerregistry.gov.eg/reports.aspx.

5. World Health Organization. 2008 - 2013 Action plan for the global strategy for the prevention and control of noncommunicable diseases [Internet]. Geneva: WHO; 2008 [cited 2011 Dec 8]. Available from: http://www. who.int/nmh/Actionplan-PC-NCD-2008.pdf?ua=1.

6. Lyons R, Langille L. Healthy lifestyles: strengthening the effectiveness of lifestyle approaches to improve health [Internet]. Dalhousie university, The Atlantic Health Promotion Research Center; Canadian Consortium of Health Promotion Research Center; 2000 [cited 2011 Oct 14]. Available from: http://www.phac-aspc.gc.ca/ph-sp/docs/healthysain/pdf/lifestyle.pdf.

7. Hansen R. Molecular epidemiology of colorectal cancer [Ph.D. thesis]. Copenhagen: University of Copenhagen, Faculty of Health Science, Environmental and Occupational Medicine Department; 2007.

8. Harriss DJ, Atkinson G, George K, Cable NT, Reilly T, Haboubi N, et al.; C-CLEAR group. Lifestyle factors and colorectal cancer risk (1): systematic review and meta-analysis of associations with body mass index. Colorectal Dis. 2009 Jul;11(6):547-63.

9. National Institute for Clinical Excellence. Guidance on cancer services improving outcomes in colorectal cancers: manual update [Internet]. London: National Institute for Clinical Excellence; 2004 [cited 2011 Nov 25]. Available from: http://www.nice.org.uk/guidance/csgcc/evidence/ improving-outcomes-in-colorectal-cancers-manual-update-2.

10. Bosetti C, Pelucchi C, La Vecchia C. Diet and cancer in Mediterranean countries: carbohydrates and fats. Public Health Nutr. 2009 Sep;12(9A):1595-600.

11. Giles GG, English DR. The Melbourne Collaborative Cohort Study. IARC Sci Publ. 2002;156:69-70.

12. U. S. Food and Drug Administration. Serving sizes of products that can reasonably be consumed at one eating occasion; updating of reference amounts customarily consumed; approaches for recommending smaller portion sizes federal register advance notice of proposed rulemaking [Internet]. Silver Spring: U.S. Food and Drug Administration [cited 2012 Jan 25]. Available from: http://www.fda.gov/Food/LabelingNutrition.

13. Elattar I. Colorectal cancer: magnitude of the problem [Internet]. Annual Cancer Conference of the Egyptian Cancer Society; 2005 [cited 2010 Nov 23]. Available from: http://www.nci.edu.eg/cancer_problem/ magnitudeofproblemcoloncancer;2005.

14. Almurshed KS. Colorectal cancer: case-control study of sociodemographic, lifestyle and anthropometric parameters in Riyadh. East Mediterr Health J. 2009 Jul-Aug;15(4):817-26.

15. van Duijnhoven FJ, Bueno-De-Mesquita HB, Ferrari P, Jenab M, Boshuizen HC, Ros MM, et al. Fruit, vegetables, and colorectal cancer risk: the European Prospective Investigation into Cancer and Nutrition. Am J Clin Nutr. 2009 May;89(5):1441-52.

16. Limsui D, Vierkant RA, Tillmans LS, Wang AH, Weisenberger DJ, Laird PW, et al. Cigarette smoking and colorectal cancer risk by molecularly defined subtypes. J Natl Cancer Inst. 2010 Jul 21;102(14):1012-22.

17. Bener A, Moore MA, Ali R, El Ayoubi HR. Impacts of family history and lifestyle habits on colorectal cancer risk: a case-control study in Qatar. Asian Pac J Cancer Prev. 2010;11(4):963-8. 
18. Arafa MA, Waly MI, Jriesat S, Al Khafajei A, Sallam S. Dietary and lifestyle characteristics of colorectal cancer in Jordan: a case-control study. Asian Pac J Cancer Prev. 2011;12(8):1931-6.

19. Alexander DD, Cushing CA. Red meat and colorectal cancer: a critical summary of prospective epidemiologic studies. Obes Rev. 2011 May;12(5):e472-93.

20. World Cancer Research Fund; American Institute for Cancer Research Food, nutrition, physical activity, and the prevention of cancer: a global perspective [Internet]. Washington DC: AICR; 2007 [cited 2012 Sep 15]. Available from: http://www.wcrf.org/sites/default/files/Second-ExpertReport.pdf.

21. Santarelli RL, Pierre F, Corpet DE. Processed meat and colorectal cancer: a review of epidemiologic and experimental evidence. Nutr Cancer. 2008;60(2):131-44.

22. Hall MN, Chavarro JE, Lee IM, Willett WC, Ma J. A 22-year prospective study of fish, n-3 fatty acid intake, and colorectal cancer risk in men. Cancer Epidemiol Biomarkers Prev. 2008 May;17(5):1136-43.

23. Sanjoaquin MA, Appleby PN, Thorogood M, Mann JI, Key TJ. Nutrition, lifestyle and colorectal cancer incidence: a prospective investigation of 10998 vegetarians and non-vegetarians in the United Kingdom. Br J Cancer. 2004 Jan 12;90(1):118-21.

24. Mizoue T, Kimura Y, Toyomura K, Nagano J, Kono S, Mibu R, et al. Calcium, dairy foods, vitamin D, and colorectal cancer risk: the Fukuoka Colorectal Cancer Study. Cancer Epidemiol Biomarkers Prev. 2008 Oct;17(10):2800-7.

25. Nayak SP, Sasi MP, Sreejayan MP, Mandal S. A case-control study of roles of diet in colorectal carcinoma in a South Indian Population. Asian Pac J Cancer Prev. 2009 Oct-Dec;10(4):565-8.

26. Chiu BC, Ji BT, Dai Q, Gridley G, McLaughlin JK, Gao YT, et al. Dietary factors and risk of colon cancer in Shanghai, China. Cancer Epidemiol Biomarkers Prev. 2003 Mar;12(3):201-8.
27. Sriamporn S, Wiangnon S, Suwanrungruang K, Rungsrikaji D, Sukprasert A, Thipsuntornsak N, et al. Risk factors for colorectal cancer in northeast Thailand: lifestyle related. Asian Pac J Cancer Prev. 2007 Oct-Dec;8(4):573-7.

28. Squires J, Roebothan B, Buehler S, Sun Z, Cotterchio M, Younghusband $\mathrm{B}$, et al. Pickled meat consumption and colorectal cancer (CRC): a casecontrol study in Newfoundland and Labrador, Canada. Cancer Causes Control. 2010 Sep;21(9):1513-21.

29. Slattery ML, Edwards S, Curtin K, Ma K, Edwards R, Holubkov R, et al. Physical activity and colorectal cancer. Am J Epidemiol. 2003 Aug $1 ; 158(3): 214-24$.

30. Hu J, La Vecchia C, Negri E, Mery L. Nutrients and risk of colon cancer. Cancers (Basel). 2010 Feb 10;2(1):51-67.

31. Sun Z, Liu L, Wang PP, Roebothan B, Zhao J, Dicks E, et al. Association of total energy intake and macronutrient consumption with colorectal cancer risk: results from a large population-based case-control study in Newfoundland and Labrador and Ontario, Canada. Nutr J. 2012 Mar 26;11:18. doi:10.1186/1475-2891-11-18.

32. Williams CD, Satia JA, Adair LS, Stevens J, Galanko J, Keku TO, et al. Associations of red meat, fat, and protein intake with distal colorectal cancer risk. Nutr Cancer. 2010;62(6):701-9.

33. Chiu BC, Gapstur SM. Changes in diet during adult life and risk of colorectal adenomas. Nutr Cancer. 2004;49(1):49-58.

34. Ramadas A, Kandiah M. Food intake and colorectal adenomas: a casecontrol study in Malaysia. Asian Pac J Cancer Prev. 2009;10(5):925-32.

35. Nashar RM, Almurshed KS. Colorectal cancer: a case control study of dietary factors, King Faisal Specialist Hospital and Researh Center, Riyadh, Saudi Arabia. J Family Community Med. 2008 May;15(2):57-64.

Received April 26, 2013

Accepted in revised form August 4, 2014 